\title{
Exploring understandings of Pacific values in New Zealand educational contexts: Similarities and differences among perceptions
}

Robin Averill

Te Herenga Waka - Victoria University of Wellington, NZ: robin.averill@vuw.ac.nz

Ali Glasgow

Te Herenga Waka - Victoria University of Wellington, NZ: ali.glasgow@vuw.ac.nz

Fuapepe Rimoni

Te Herenga Waka - Victoria University of Wellington, NZ: fuapepe.rimoni@vuw.ac.nz

\begin{abstract}
Case studies exploring how educational policies can help teachers serve learners disadvantaged through cultural marginalization are urgently needed to inform education systems internationally. The study reported here explored perceptions of Pacific cultural values at the heart of education policy in New Zealand that were intended to improve opportunities of learners with Pacific heritage. Participants included early childhood, primary, secondary, and tertiary teachers of Pacific and non-Pacific heritage. Data included interviews and teaching observations. Results indicate that the Pacific values can be more deeply felt, understood, and enacted by Pacific teachers than their non-Pacific counterparts. Results are discussed in relation to tenets of culturally sustaining pedagogy and aspects of the Pacific-based Fonofale model. Implications of this work include that initial and in-service teacher education must assist teachers to develop working understandings of values as they are felt and experienced by policy target groups. This study contributes to the literature by discussing how a culturally-embedded model can be a useful tool towards ensuring teachers can understand cultural nuances inherent within educational policy and align their practice with these.
\end{abstract}

Keywords: policy; cultural values; Pacific nations; teacher perspectives; initial teacher education; teacher professional development

\section{INTRODUCTION}

Quality education is essential for ensuring all learners enjoy achievement that maximizes their study and life opportunities. Enhancing the educational experiences of learners susceptible to marginalization because their cultural heritage differs from that of the dominant cultural group is the focus of educational policy initiatives in many countries (e.g., Australia, Canada, United States). Common challenges to implementation of such policies include complexities of learners' lives, widespread lack 
of relevant cultural knowledge among many teachers, historically-bound educational systems and processes, and conflicting understandings and priorities amongst stakeholders (Baeza, 2019; Hynds et al., 2015; Riddle, 2019). In New Zealand, education policy highlights the centrality for Pacific learners of a collection of Pacific ${ }^{1}$ values (Ministry of Education, 2013, 2018). For example, Tapasā: Cultural competencies framework for teachers of Pacific learners (Ministry of Education, 2018) describes that educational success for Pacific learners:

[I]s achieved when teachers recognise and build on what Pasifika learners, their parents, families, and communities already understand, value and what they know; and integrate those understandings, values and knowledge into their planning and teaching practices. (p. 3)

While the idea of generic values being put forward as important across New Zealand's Pacific groups may be debated, understanding the breadth of significance and interpretation of the values presented in policy documents is important to inform implementation and further policy development. To date, however, as in many international contexts, the research and guidance necessary for informing educators regarding how they can strongly demonstrate such policy is limited. Research is needed to help inform policy implementation and teacher practice to ensure those working in educational contexts can, for example, "celebrate, develop and support the lives of Pacific peoples as both unique and connected wherever they are" (Sanga \& Reynolds, 2017 , p. 202). In this article, we describe our study which explored educator perceptions of Pacific cultural values, offer findings in relation to how teachers can work towards ensuring they can celebrate, develop, and support the lives of Pacific learners, and draw conclusions relevant to other countries with policies designed to enhance practice for culturally marginalized learners.

We describe the context of, rationale for, and nature of our study (Averill \& Rimoni, 2019; Rimoni \& Averill, 2019), linking to international literature focussing on the implementation of culturally sustaining practice. We provide an overview of our results showing how the Pacific values were interpreted similarly and differently by participants with and without Pacific heritage (referred to in this article as "Pacific" and "non-Pacific"). We discuss examples from the data which show how the Pacific values can be enacted and nurtured in culturally sustaining ways in early childhood, primary, secondary, and tertiary learning settings. We finish with a discussion of implications of this work for New Zealand and international contexts.

\section{The New Zealand context}

Great diversity exists across New Zealand's Pacific population, with some New Zealand people with Pacific heritage having lived in New Zealand for many generations and others of families who have recently migrated. Two thirds of New Zealand's Pacific population are New Zealand born (Statistics New Zealand, 2014). Having migrated

\footnotetext{
${ }^{1}$ The term 'Pasifika' is used by the New Zealand Ministry of Education "to categorise trans-culturally diverse peoples from the Pacific regions who now live in New Zealand but continue to have family and cultural connections to Pacific Island nations. Pasifika identify themselves with the islands and cultures of Samoa, Tonga, Cook Islands, Fiji, Niue, Tokelau, Tuvalu, and other Pasifika heritages" (Ministry of Education, 2018, p. 5). In this article, we use the term "Pasifika" as suitable for quotes and as it has been used by others whose work we are referring to. Otherwise, we use the term "Pacific" to describe those in New Zealand with heritage from these Pacific countries.
} 
from countries of the South Pacific, the New Zealand Pacific population include people of Samoan, Cook Island Māori, Tongan, Niuean, Fijian, Tokelauan, and Tuvaluan heritage.

There is disparity across all of New Zealand's educational sectors regarding the proportions of learners and educators who have Pacific heritage. For example, across the New Zealand primary and secondary school sectors, over three times the number of learners have Pacific heritage than teachers (Education Counts, 2019; Education Review Office, n.d.). Such statistics indicate only a broad overview, with Pacific learners' experiences of being taught by people with Pacific heritage highly variable. In the early childhood sector, typically everyone involved in Pacific language nests-learners, teachers, and families - have Pacific heritage, while Pacific learners in other early childhood contexts may not experience teachers with Pacific heritage at all in their early childhood education. Pacific learners may or may not be taught by teachers with Pacific heritage within their schooling, and in some tertiary contexts, some Pacific learners may never be taught by lecturers with Pacific heritage.

The early childhood and school curricula are intended to reflect New Zealand's cultural diversity and to value the histories and traditions of all New Zealanders (Ministry of Education, 2007, 2017). For example, the early childhood curriculum, Te Whāriki, is intended to support:

[C]hildren from all backgrounds to grow up strong in identity, language and culture. In this context, Te Whāriki specifically acknowledges the educational aspirations of Pasifika [New Zealand Pacific] peoples, who derive their identities from Pacific Island nations. (Ministry of Education, 2017, p. 7)

Many New Zealand tertiary institutions also strive to reflect, support, and show they value Pacific students and their cultures towards ensuring learners with Pacific heritage feel welcome, that they belong, and that the institution is a place where they can succeed personally and academically (e.g., Victoria University of Wellington, n.d.). However, despite these emphases on attention to Pacific learners and their cultures across educational sectors, long-standing disparity in educational experience and achievement continues between New Zealand students of Pacific and non-Pacific heritage (e.g., Caygill et al., 2016; Glasgow \& Rameka, 2017; Mara, 2017; New Zealand Qualifications Authority, 2019), demonstrating the urgency for improvement in all teachers' understandings of how to maximize educational opportunities for Pacific learners.

Targeted within early childhood, primary, and secondary school contexts, the Pasifika education plan (Ministry of Education, 2013) and Tapasā: Cultural competencies framework for teachers of Pacific learners (Ministry of Education, 2018) are intended to enhance educational opportunities for Pacific learners by supporting non-Pacific teachers "to engage with Pacific learners in culturally responsive ways" (p. 1). Central to these policy documents, and to the 'Pasifika Success Compass' (Ministry of Education, 2018, p. 4) are values stated as important across Pacific groups: respect, service, leadership, family, reciprocal relationships, inclusion, belonging, spirituality, and love. Teachers are expected to reflect "the importance of retention and transmission of Pacific identities, languages and cultural values" (Ministry of Education, 2018, p. 10) in their teaching. While the policy documents encourage readers to acknowledge differences that exist amongst Pacific heritage groups, explanation regarding how these 
differing groups may perceive the values is not included. Furthermore, implementation of education policy intended to reduce educational inequities can be challenging in itself, particularly when the ethnicities of teachers and learners are poorly matched (e.g., Hynds et al., 2015). While policy requirements can increase teachers' knowledge of specific cultural groups and their expectations of needing to teach in ways responsive to this knowledge, the diversity across such groups and varying quality of professional development programmes can limit teachers' capabilities and understanding of how to effectively and suitably teach specific learner groups (Baeza, 2019). In addition, with the values stated in English in the policy documents, it is possible that non-Pacific teachers may misinterpret or underestimate the meanings held of the values by Pacific people.

\section{Education policy and culturally sustaining teaching}

Culturally sustaining practices (Paris, 2012) and asset-based approaches (CeledónPattichis et al., 2018; Reynolds, 2018) are advocated towards improving the teaching of learners of groups currently underserved in educational settings. Culturally sustaining pedagogical practices are those that can foster, perpetuate, and sustain "linguistic, literate, and cultural pluralism" (Paris, 2012, p. 93) within educational contexts. Assetbased approaches are based on the belief that students', families', and communities' ways of knowing and being are intellectual resources that can contribute greatly to teaching and learning (Civil, 2017). Approaches such as these are intended to enrich learners' feelings of engagement with their cultural heritage by ensuring the knowledge, values, and perspectives associated with students' heritage cultures are strongly reflected within teaching practices and the taught curriculum. To teach in these ways in relation to Pacific heritages, New Zealand teachers need strong knowledge and understanding of Pacific learners (Allen \& Robertson, 2009; Chu et al.2013; Ferguson et al., 2008; Rimoni, 2016; Spiller, 2012). However, we know that teachers can be unaware of their students' values and can hold stereotypical views of students who are of ethnic groups other than their own (Rubie-Davies, Hattie, \& Hamilton, 2006). In addition, Pacific cultures are dynamic and evolving (Anae, 2001; Coxon \& Wendt Samu, 2010; Hunkin-Tuiletufuga, 2001), hence ongoing attention to the development of teacher knowledge and understandings of Pacific cultures is important for ensuring cultural knowledge is current. Although reflecting Pacific values in classroom practice can help maximize Pacific learner success (Hunter et al., 2016), Pacific values are "rarely identified by schools as valuable in the classroom context" (Fa'avae, 2017, p. 51). In summary, while the nature of pedagogies and behaviours associated with culturally sustaining practice are clear, teachers may not know about or recognize Pacific values; they may see them as generic rather than nuanced, they may not realize that the values can change over time, or they may either not appreciate the values or not convey to others the appreciation they do have for them.

\section{The Fonofale model}

Used in relation to Pacific people, Pulotu-Endemann's (1998/2001) Fonofale represents health matters metaphorically as a fale, a traditional Samoan house. The structures that comprise the fale represent factors important for the overall health of a Pacific person. The Fonofale model was chosen for use in our study as it is a traditionally-based Indigenous model in which the ideas and metaphorical setting align well with the values from the contemporary New Zealand-based Tapasā compass (Ministry of Education, 
2018) that we wanted to explore. A Samoan fale is a home, a community, or church-a safe environment that provides a sense of belonging, leadership, and spirituality. From this structure, the fale serves to be the place that helps instil values, such as respect, reciprocity, and other inclusive values. Without a strong foundation, the family or community will not function morally and inclusively (Faitaua, 2014). The foundation of the fale represents family, the foundation for people of all Pacific cultures. The roof represents beliefs and cultural values, which are considered to be the shelter for one's life. The four posts between the foundation and roof are used to represent the spiritual, physical, mental, and other aspects of life, that together form the connections between family and culture. Surrounding the fale is a cocoon that represents the environment, time, and context, all of which can have direct or indirect influence on an individual (Pulotu-Endemann et al., 1995). The decision to use the Fonofale model was affirmed as we proceeded with our data collection, in that the values inherent in the fale were being expressed by our Pacific and non-Pacific participants to varying degrees. Due recognition was accorded, however, that while the model captures one epistemological worldview, it may not necessarily encompass the range or totality of worldviews of the two non-Samoan researchers nor that of Pacific participants. Nevertheless, it was deemed to provide a strong metaphor that shows sufficient alignment with the research focus.

In summary, disparity between the proportions of learners and educators who have Pacific heritage exists in most New Zealand educational contexts, and research indicates that many New Zealand educators, as for New Zealand society more widely, lack deep understanding of Pacific cultural knowledge. The Fonofale model provides a culturallylocated lens for considering our findings. Across early childhood to tertiary contexts, most New Zealand educational institutions desire or are required to strongly reflect Pacific values towards ensuring comfortable engagement and academic success of Pacific learners. To help inform and enhance teaching of New Zealand Pacific learners, our study explored the research question:

What are the similarities and differences between Pacific and non-Pacific educators' perceptions of the Pacific values and the ways in which they demonstrate and nurture these values in their teaching?

Next, we describe the study, outline selected results, and then discuss implications of this work for educators working within and outside of New Zealand.

\section{THE STUDY}

We explored perceptions of the Pacific values of educators across early childhood, primary, secondary, and tertiary contexts. The values of respect, leadership, and service were explored in the first year of the study, and family, spirituality, and reciprocal relationships in the second year. Pasifika education research guidelines (Anae et al., 2001) were used to inform the study design. For example, researchers negotiated data gathering times and locations with participants, drew from established relationships, and were flexible and ready to compromise. The three researchers comprised the research team, one each of Samoan, Kuki Airani/Tahiti, and New Zealand European heritage. Full ethics approval was gained for this study and all participants gave full informed consent. 
Data was collected from a total of 32 Pacific and nine non-Pacific teachers across three early childhood centres (two language nests and one English-medium setting), ten English-medium schools (seven primary and three secondary), and one large tertiary institution. There were varied proportions of Pacific learners and teachers across the data gathering settings, reflecting the diversity of proportions of Pacific learners across learning institutions in New Zealand. Study participants were identified by the researchers or the institution leader as educators who were making a positive difference for Pacific learners. The heritage Pacific Nations of study participants were roughly consistent with New Zealand population proportions.

Semi-structured interviews were used to explore what each of the values meant to participants and how they believed they demonstrated and nurtured the values in their teaching. Using observation schedules with key indicators drawn from consultation based on elements from a wide range of Pacific and non-Pacific based literature, enactment of the values in teaching and other educator interactions with students was recorded across several lessons of each teacher. Interviews were mostly carried out prior to teaching observations to establish connections and comfort between the educator and researcher/s and to enable observations to be informed by understanding the participant's perspectives. In other cases, interviewers drew from the teaching observations during the interview.

Interviews were carried out with three early childhood leaders (Pacific), eight early childhood teachers (Pacific), one school principal (non-Pacific), 12 primary teachers (five Pacific, seven non-Pacific), ten secondary school teachers (five Pacific, five nonPacific), one teacher aide (non-Pacific), and three university lecturers (two Pacific, one non-Pacific). All interviews were transcribed. Heritage ethnicities of Pacific participants included Cook Islands, Samoa, Tahiti, and Tokelau. Data were gathered by two researchers together in one school and individually in the other settings. Analysis was carried out by the researchers independently reading and rereading the interview and observation data and then together determining key themes.

\section{Results}

To give a broad overview of participants' perceptions and actions, the results are discussed by education sector with indicative examples from each data set for one of the focus values. Themes across sectors are then discussed. Themes were drawn considering both interview and observational data. Results are discussed in light of the ideas shared and how these were shared. It is possible that the communication styles of Pacific and non-Pacific participants differed, particularly in relation to the expression of emotions.

\section{Early childhood educators: The cultural value of spirituality}

All early childhood teachers interviewed were of Pacific heritage. Spirituality is the focus value of this section as it was viewed by the early childhood Pacific participants as a key value in the lives of Pacific people. Toso (2011) explains that spirituality is an important concept for understanding ways that Samoan children and adults relate to each other. While its expression may vary between and within Pacific cultures, spirituality is a widely held, cross-cultural value across the Pacific. Spirituality contributes to the total well-being of the Pacific person. Spirituality is a value promoted 
and espoused within Te Wharriki, the early childhood curriculum (Ministry of Education, 2017), which acknowledges the centrality of Te Taha Wairua, the spiritual dimension, in the development of the whole child (p. 67).

An early childhood teacher in a Cook Islands Pacific language nest described the prominent place of spirituality in Pacific lives:
Spirituality is built into all parts of our lives. We foster the importance of religious Christian practice in our early childhood programme as a collective activity. At our group sessions we build in spiritual principles and rituals such as Pure (Prayers) and Himene (Religious hymns). In this, we remember our ancestors who have passed. It also builds in our children a strong sense of cultural identity and belonging.

A Tokelauan language nest teacher explained her view that promoting spiritual values and beliefs dovetailed with traditional cultural practices such as Inati (a Tokelauan practice of sharing resources and caring for others in the community):

It is how we were brought up - to look after our fanau and to nourish our children's spirituality. We build spirituality into our daily programme beginning with a karakia (prayer). It doesn't feel complete [starting our day] without it. Our children attend funerals at the hall next door. We go to pay our respects.

In these ways children are learning traditional religious rites and practices which may then be "played out" in their learning environments. A Tokelauan teacher described how children demonstrate their understandings of spirituality and religious practice through their early childhood play based programme:
After one funeral some of the children [in their play] set up an altar on the mat and simulated the funeral ritual of saying farewell to the deceased community member. I felt quite emotional when I saw this as it is an important part of their culture and practice. Our children were demonstrating their cultural and spiritual understandings [independently, without adult intervention].

A Samoan teacher within an English-medium setting noted that as the head teacher she fostered spirituality within the centre's programme. She noted that although the centre was "Western", she built in Pacific spiritual practices:

We begin with opening prayers and we always bless the food. We foster the importance of attending church and we prepare children for White Sunday church services.

This teacher noted that although some of the parents were accepting of spirituality and of saying lotu (prayers), others, particularly the non-Pacific teachers and parents, were not as comfortable with expressions of spirituality. She described that this group were concerned about their lack of knowledge and that they "were worried about if they didn't do it right".

The importance of ensuring that children are well equipped with cultural, spiritual, and religious values before they leave the early childhood setting for school was voiced by a Tokelauan teacher. This teacher expressed concern that children's spiritual nurturing may not continue through the English-medium education system, and sometimes felt concerned about children leaving the language nest and transitioning to school: 
If we don't plant the foundations [of spirituality] children will miss out. Sometimes I don't feel safe to let them go.

A Samoan teacher in an English-medium centre summed up the feelings of many by saying that, for her, having a strong spiritual belief and value base gave her the "heart to teach" both Pacific and non-Pacific children.

\section{Primary educators: The cultural value of service}

Our interview data indicated that service is a value very important and always relevant to many Pacific people, including Pacific teachers, learners, and their families. Pacific and non-Pacific teachers held some similar beliefs about the importance of service:

[Service is] the love for the kids and their learning ... that's the biggest thing for me. You know, providing a service that scaffolds these kids' learning to be successful in life ... . if they make progress and succeed it will be a big success for them, the fanau, the church, because we are not individuals, we represent the church, the community, the village. (Pacific primary educator)

If I didn't value service, I wouldn't be in this role. I'm a servant to [the students] . . . I see [service] is one of the biggest values I'd like to see developed with them, and if I'm not demonstrating it, then I can't really expect it. (Non-Pacific primary educator)

The connection of service to Pacific students' learning and to being successful were important for Pacific and non-Pacific teachers. Providing Pacific learners with the responsibility of and opportunity to give service through helping others was discussed by both Pacific and non-Pacific teachers as helping Pacific students to be and feel valued. More frequent opportunities for students to take on service type roles were noted in Pacific teachers' classrooms than those of non-Pacific teachers.

Teachers all shared their understanding of service as giving to others, and that their roles as teachers included serving learners by taking responsibility for leading and managing the learners and learning in their classrooms. Pacific teachers more often spoke of this role as one that extends to encompass involvement of learners and parents. For example, one Pacific teacher explained that ensuring students were ready to learn within holistic three-way relationships (teacher, learner, parents) was involved in how she interpreted service:

Service - is a three-way job, it's a service to the students, with the parents and the teachers, all three aspects connect to the students being ready and valued. We can't do this without the parents and we can't do it without the students (Pacific primary educator)

Service was demonstrated by the primary school teachers through providing support, opportunity, and space for Pacific students to develop and grow as learners and people and to be of service to their peers. One teacher discussed that providing service enabled her to learn about her learners and their lives:

Acts of service (or a serving orientation to life) take you outside yourself and your own little sphere to new communities and people who can teach you much about yourself, as well as about life as you do not know it. (Non-Pacific primary educator) 
Pacific teachers discussed service more widely and broadly than their non-Pacific counterparts in relation to their roles as teacher and within their family and wider community groups. Such explanations and our classroom observation data showed Pacific teachers being more likely than non-Pacific teachers to strongly and consistently reflect broad, ingrained, Pacific community-held considerations of service in their teaching.

\section{Secondary educators: The cultural value of family}

Family also emerged from interview data as vitally important to Pacific teachers. One Pacific secondary educator shared that to her and many Pacific people, the value of family is the most important thing:

I would say family is probably more important than anything else, for me personally. There is this kind of - it is not really a saying, but a thing that some Pacific Islanders say - and it is like "family to loyalty". It means "family to the death" ... what it means is that they would choose to protect and uphold and maintain that family kind of unit above other things. (Pacific secondary educator)

Another Pacific secondary educator spoke similarly about the value of family to her and her family:

To me it's everything, it's at the core with my faith. Everything I do is for the family; family is at the forefront and the centre of everything. My parents would say "you carry your family's name everywhere you go and so your actions affect and come back to the family". It is almost like a way to try and keep you on the straight and narrow, not to go out of those boundaries and not to bring shame or give your family a bad reputation. (Pacific secondary educator)

These educators talked of the role families hold in relation to the success of Pacific students, sharing that Pacific students feel that their success is to make their families proud, rather than seeing their success for themselves personally. Families of Pacific students and Pacific educators demonstrated the value of family and personal achievements being family achievements by attending and helping with school events, such as a Pacific Success evening. Observations showed that in discussing learning and behaviour with Pacific students, Pacific educators draw on students' pride in who they are and their families, such as by asking them questions like: "what would your Mum think?".

In contrast, non-Pacific educators spoke of the importance to them of the value of family in personal rather than community ways, and were less emphatic than their Pacific counterparts:

I know for me; family are the people who you are close to - either through choice or through blood. (Non-Pacific secondary educator)

There is the element of respect there and family is really important, and we do things for one another and we care about one another and we want the best for one another, and we pitch in and help. (Non-Pacific secondary educator)

Both Pacific and non-Pacific educators likened their teaching practice and interactions to family experiences; one non-Pacific educator reporting drawing from the ways his parents had held high expectations for and supported his own learning in his work. Another non-Pacific educator explained that "we look at our kids individually like you 
do in family, we are all going one place together and we are not going to leave anyone behind".

\section{Tertiary educators: The cultural value of respect}

Respect has emerged from many studies as an essential value to Pacific learners (e.g., Ferguson et al., 2008; Spiller, 2012). While all tertiary educators in the study felt strongly about the importance of respect, overall, the Pacific tertiary educators spoke more deeply and broadly of respect and taught in ways reflecting respect more deeply than the non-Pacific educator. One Pacific tertiary educator described the Pacific value of respect as including the:

[N]otion of empathy and looking at [situations] from the other person's perspective ... considering the wealth of knowledge, and strengths and skills that this person can bring, and this community can bring ... [teacher] humility is an important starting point in terms of that respectful relationship. (Pacific tertiary educator)

This educator explained that to her, respect demonstrated in practice will:

[E]ngender respect from the community, and [provide] that sense of "we're valued, we feel valued, you value us, and our children aren't going to lose their sense of identity, they're going to retain who they are, and be proud of it as well ... showing that we really want to ensure that children do retain that strong sense of identity, those Pacific languages and cultural practices. (Pacific tertiary educator)

This educator's teaching strongly demonstrated and highlighted the importance of the value of respect. She incorporated Pacific greetings and protocols, deliberately and specifically focussed on explaining the importance of relationships for developing effective communication, and explained culturally-linked examples of how respect can be shown (e.g., how facial expressions and gestures may be interpreted differently by different groups). This educator used students' names, encouraged respectful behaviours in the students (e.g., emphasized the important of correct pronunciation of names), and helped them to consider the feelings of people from cultural groups other than their own within lecture content. Another Pacific tertiary educator discussed her ideas of respect having come directly from her upbringing over many years of being shown and told the family's expected ways of being and interacting with others. She discussed demonstrating respect by prioritizing relationships with learners over content, especially in initial lectures, and using interactive teaching strategies and humour to ensure students were comfortable to participate and learn.

The non-Pacific tertiary educator explained that to demonstrate respect in her teaching she "would know every single [Pacific student] by name, follow up on their lives, ask them what schools they were at", and work to make deliberate connections with them by identifying Pacific people she and they may know in common. She described how her knowledge of Pacific Nations, priorities, and issues enabled her to bring Pacificbased examples into her teaching and to be empathetic to factors affecting her students' learning. In her teaching, this educator demonstrated respect by greeting students and introducing herself personally and professionally in relation to the lecture content focus. She expected, encouraged, and supported students to contribute and interact with one another in pairs, small groups, and with the wider lecture group. She used positive body language, listened intently to student ideas, and acknowledged factors potentially impacting on their learning (e.g., financial situation, wellbeing, time management). 


\section{Themes across sectors}

The results above give examples of participants' views and how they teach. There were similarities and differences in the ways that Pacific and non-Pacific participants described their feelings. All responses showed that the values were important to participants and felt important for them to demonstrate and nurture. Pacific participants were often more emotional and emphatic than non-Pacific participants in the way that they spoke about specific values (e.g., respect, family). For example, several Pacific participants cried while describing how strongly they felt specific values were to them, with their tears sometimes linked to their concerns about negative experiences of Pacific learners, and sometimes to the deep connections they have with Pacific family and community members. Pacific teachers were more likely than non-Pacific participants to emphasize how a value was also of strong importance to their family and community, and were more likely to affirm the importance of our study for helping to inform New Zealand educators, indicating to us their concerns that non-Pacific teachers do not fully understand Pacific perceptions of the values.

\section{DISCUSSION}

Our findings demonstrate that universal views of the values were not held within or across the Pacific and non-Pacific participants. However, findings show that while some similarities exist, the values are often more deeply expressed and more deeply demonstrated in practice by Pacific educators. Pacific educators were more likely to include discussion of thoughts and feelings of Pacific learners and community than nonPacific educators. They were also more likely to discuss implications for learners of responsiveness to the values than their non-Pacific counterparts, whose responses in the main were about teacher actions.

No participants questioned the values explored, either as values important to people with Pacific heritage or as potentially having different meanings for people of different Pacific heritages. This result suggested to us that either participants were aware of and comfortable with the values as given in the policy documents, or that they were unaware of these but comfortable with them as important for Pacific people in general. Differences in descriptions and actions between Pacific and non-Pacific educators may be linked to differences in communication styles and norms between the two groups. However, our findings suggest that Pacific learners taught by non-Pacific educators need to navigate educational settings that may not reflect the Pacific values as strongly as they experience them outside formal education.

We surmise that the commonality of the English language across policy, researchers, and the research settings may have led Pacific participants to use English terms for the values rather than terms in their heritage language. Our findings indicate that Pacific learners would benefit from stakeholders in their educational setting developing shared understandings of the values most important to the setting's Pacific community. Further research would be useful to explore how shared understandings of values can be generated and strongly reflected in educational settings, including the extent to which using Pacific language terms for the values could assist. 
Our findings highlight the importance of interrogating ideas from contemporary academic context-based Western models (e.g., the Tapasa $\bar{a}$ compass, Ministry of Education, 2018) using Indigenous tools. We found that Pacific teachers' responses and teaching was much more aligned to the metaphorical, holistic, and integrated perspectives of the Fonofale model (Pulotu-Endemann, 1998/2001) than those of nonPacific teachers, and than afforded by expression of the values in Tapasa $\bar{a}$ (Ministry of Education, 2018). Our data provides illustrative examples from practice of both the Fonofale and Tapas $\bar{a}$ models that can assist teachers' work with Pacific learners and their families, and shows that nuance and diversity exist in people's perceptions of key aspects of these.

We have examined perspectives of cultural values - only one aspect of the education policy focussed on Pacific learners (Ministry of Education, 2013, 2018). Considering our results in light of the Fonofale model, culturally sustaining pedagogy, and assetbased approaches, our findings indicate there is much work to be done to ensure all New Zealand teachers can implement education policy suitably for Pacific learners.

\section{CONCLUSION}

The Pacific values are fundamental to New Zealand education policy and practice. Our findings indicate that Pacific teacher participants saw Pacific values as vital, always important to and expected of them. We have provided evidence that the values are culturally embedded; understood and enacted differently by New Zealand Pacific and non-Pacific teachers. Improving consistency in interpretation and enactment of the Pacific values is necessary for policy to be implemented and for disconnects between the school and out-of-school lives of Pacific learners to be reduced. Further research could help illuminate similarities, differences, and nuances across perspectives on values important to specific New Zealand Pacific groups.

Our work provides glimpses that can inform teachers, learners, and parents about how the Pacific values can be strongly demonstrated in learning settings. However, further study is needed to explore how best to enhance non-Pacific teachers' understanding and enactment of the Pacific values in ways that enhance learning experiences for Pacific learners and promote Pacific learner achievement.

Internationally, our study indicates that policy intended to improve educational opportunities for marginalized students may be interpreted differently by different readers and stakeholders and that it is important to interrogate such policy using Indigenous tools. Our study design provides a basis for comparing perspectives towards informing policy development and professional development of teachers of learners of cultures other than their own. We believe that understanding and developing teachers' perceptions of values fundamental to how these learners and their families think, feel, and act are essential for implementation of equity-based pedagogies and approaches (e.g., Celedón-Pattichis et al., 2018; Paris, 2012).

Learning institutions have many dimensions of complexity-diverse learners embedded within diverse communities within complex societies. All involved in education are responsible for ensuring learner success, and for doing all they can to celebrate, develop, and support the lives of their learners. We hope our work can contribute to teachers celebrating, developing, and supporting the lives of their Pacific learners, and 
marginalized learners more widely, and can inform those responsible for developing and implementing equity-focussed education policy.

Acknowledgements: The research team are grateful for an internal research grant from Te Herenga Waka - Victoria University of Wellington which helped fund the research reported in this article.

\section{REFERENCES}

Allen, P., \& Robertson, J. (2009). "In order to teach you, I must know you." The Pasifika initiative: A professional development project for teachers. New Zealand Journal of Educational Studies, 44(2), 47.

Anae, M. (2001). The new Vikings of the sunrise: New Zealand-borns in the information age. In C. Macpherson, P. Spoonley, \& M. Anae (Eds.), Tangata o Te Moana Nui: The evolving identities of Pacific peoples in Aotearoa/New Zealand (pp. 101-121). Dunmore Press.

Anae, M., Coxon, E., Mara, D., Wendt-Samu, T., \& Finau, C. (2001). Pasifika education research guidelines. Wellington: Ministry of Education.

Averill, R., \& Rimoni, F. (2019). Policy for enhancing Pasifika learner achievement in New Zealand: Supports and challenges. Linhas Críticas, 25, 549-564. htpps://doi.org.10.26512/lc.v25i0.23780

Baeza, A. R. (2019). Teachers' professional standards and Indigenous Education in Australia and Chile. The International Education Journal: Comparative Perspectives, 18(3), 14-24.

Caygill, R., Hanlar, V., \& Singh, S. (2016). TIMSS 2014/15: Mathematics Year 9: Trends over 20 years in TIMSS. Wellington, New Zealand: Ministry of Education.

Celedón-Pattichis, S., Borden, L., Pape, S., Clements, D., Peters, S., Males, J. Chapman, O., \& Leonard, J. (2018). Asset-based approaches to equitable education research and practice. Journal for Research in Mathematics Education, 49(4), 373-389. https://doi: 10.5951/jresematheduc.49.4.0373

Chu, C., Glasgow, A., Rimoni, F., Hodis, M., \& Meyer, L. (2013). An analysis of recent Pasifika education research literature to inform improved outcomes for Pasifika learners (Report to the Ministry of Education). Wellington, New Zealand: Ministry of Education.

Civil, M. (2017). Preface. In S. Celedón-Pattichis, D. Y. White, \& M. Civil (Eds.), Access and equity: Promoting high quality mathematics in pre-K-Grade 2 (pp. vviii). Reston, VA: National Council of Teachers of Mathematics.

Coxon, E. \& Wendt Samu T., (2010). Pacific education research: New directions. MAI Review, 1-4. 
Education Counts. (2019). Teaching staff: Information on teaching staff in schools from 2004-2017. Wellington, New Zealand: Ministry of Education.

Education Review Office. (n.d.). Ethnic diversity in New Zealand state schools. Wellington, New Zealand.

Fa'avae, D. (2017). Family knowledge and practices useful in Tongan boys' education. Set: Research Information for Teachers, 2, 49-56. htpps://doi.org.10.18296/set.0082

Faitaua, A. (2014, October). Modern learning pedagogy + Modern Pasifika learners $=$ 21st Century Pasifika learners raising a village. http://blog.coreed.org/blog/2014/10/modern-learning-pedagogy-modern-pasifika-learners-21stcentury-pasifika-learners-raising-a-village.html

Ferguson, P. B., Gorinski, R., Wendt Samu, T. \& Mara, D. (2008). Literature Review on the experiences of Pacific learners in the classroom. Report for the Ministry of Education. Wellington, New Zealand: Ministry of Education.

Glasgow, A. H., \& Rameka, L. (2017). Maori and Pacific infant and toddler cultural pedagogy: Reclaiming a cultural lens. International Critical Childhood Policy Studies 6(1), 80-95.

Hunkin-Tuiletufuga, G. (2001). Pasefika languages and Pasefika identities: Contemporary and future challenges. In C. Macpherson, P. Spoonley, \& M. Anae (Eds.), Tangata o te moana nui: The evolving identities of pacific peoples in Aotearoa/New Zealand (pp. 196-211). Dunmore Press.

Hunter, J., Hunter, R., Bills, T., Cheung, I., Hannant, B., Kritesh, K., \& Lachaiya, R. (2016). Developing equity for Pasifika learners within a New Zealand context: Attending to culture and values. New Zealand Journal of Educational Studies, 51(2), 197-209. htpps://doi.org.10.1007/s40841-016-0059-7

Hynds, A., Averill, R., Penetito, W., Meyer, L., Hindle, R., \& Faircloth, S. (2015). Examining the impediments to indigenous strategy and approaches in mainstream secondary schools. International Journal of Leadership in Education, 19(5), 534556. htpps://doi.org.10.1080/13603124.2015.1051130.

Mara, D. (2017). Voyaging the oceanic terrains: Sustainability from within Pasifika early childhood education. Waikato Journal of Education: Te Hautaka Matauranga o Waikato, 22 (1), 37-43. htpps://doi.org.10.15663/wje.v22i1.554

Ministry of Education. (2007). The New Zealand curriculum. Wellington, New Zealand:.

Ministry of Education. (2013). Pasifika education plan 2013-2017. Wellington, New Zealand.

Ministry of Education. (2017). Te Whariki: He whariki matauranga mo nga mokopuna o Aotearoa. Wellington, New Zealand.

Ministry of Education. (2018). Tapasā: Cultural competencies framework for teachers of Pacific learners. Wellington, New Zealand. 
New Zealand Qualifications Authority. (2019). Annual report on NCEA and New Zealand Scholarship data and statistics 2018. Wellington, New Zealand.

Paris, D. (2012). Culturally sustaining pedagogy: A needed change in stance, terminology, and practice. Educational Researcher, 41(3), 93-97. htpps://doi.org.10.3102/0013189X12441244

Pulotu-Endemann, F. K. (1998/2001). Pacific mental health services and the workforce: Moving on the blueprint. Wellington, New Zealand: Ministry of Health.

Pulotu-Endemann, F. K., Crawley, L., \& Stanley-Findley, R. T. U. (1995). Strategic directions for the mental health services of Pacific islands people. Wellington, New Zealand: Ministry of Health.

Reynolds, M. (2018). They always have my back: A strengths-based approach to understanding the value(s) of Pasifika brotherhoods in education in Aotearoa New Zealand. International Journal of Multicultural Education, 20(2), 1-23. htpps://doi.org.10.18251/ijme.v20i2.1515

Riddle, S. (2019). Democracy and education in contemporary local-global contexts. The International Education Journal: Comparative Perspectives, 18(1), 1-6.

Rimoni, F. (2016). Tama Samoa stories: Experiences and perceptions of identity, belonging and future aspirations at secondary school. (Unpublished $\mathrm{PhD}$ thesis). Victoria University of Wellington, New Zealand.

Rimoni, F. \& Averill, R. (2019). Respect: A value vital for Pasifika learners. Set: Research Information for Teachers, 3, 3-11. htpps://doi.org.10.18296/set.0146

Rubie-Davies, C. M., Hattie, J., \& Hamilton, R. (2006). Expecting the best for New Zealand students: Teacher expectations and academic success. British Journal of Educational Psychology, 76, 429-444. htpps://doi.org.10.1348/000709905X53589

Sanga, K., \& Reynolds, M. (2017). To know more of what it is and what it is not: Pacific research on the move. Pacific Dynamics: Journal of Interdisciplinary Research, 1(2), 198-204.

Spiller, L. (2012). "How can we teach them when they won't listen?": How teacher beliefs about Pasifika values and Pasifika ways of learning affect student behaviour and achievement. Set: Research Information for Teachers, 3, 58-66.

Statistics New Zealand. (2014). 2013 Census QuickStats about culture and identity. Wellington, New Zealand.

Toso, V. M. (2011). Reconceptualising spirituality as a philosophy of practice for Pasifika early childhood education in New Zealand: A Samoan perspective. Pacific-Asian Education, 23(2) 129-138.

Victoria University of Wellington. (n.d.). Pasifika at Victoria University of Wellington. Wellington. 
(c) $(1) \Theta$

4.0 International License. To view a copy of this license,

visit http://creativecommons.org/licenses/by-nd/4.0/ or send a letter to Creative Commons, PO Box 1866, Mountain View, CA 94042, USA

Authors and readers are free to copy, display and distribute this article with no changes, as long as the work is attributed to the author(s) and the International Education Journal: Comparative Perspectives (IEJ: CP), and the same license applies. More details of this Creative Commons license are available at https://creativecommons.org/licenses/by-nd/4.0/. The IEJ: CP is published by the Oceania Comparative and International Education Society (formerly ANZCIES) and Sydney Open Access Journals at the University of Sydney. Articles are indexed in ERIC, Scimago Journal (SJR)Ranking / SCOPUS. The IEJ:CP is a member of the Free Journal Network: https://freejournals.org/

Join the IEJ: CP and OCIES Facebook community at Oceania Comparative and International Education Society, and Twitter: @OceaniaCIES 